\title{
Determination of the Triacylglycerol Composition of Coffee Beans by Reverse-phase High-performance Liquid Chromatography
}

\author{
Gulab N. Jham, ${ }^{* 1}$ Boryana Nikolova-Damyavova, ${ }^{2}$ Mirtes Viera, ${ }^{1}$ Ricardo Natalino ${ }^{1}$ and \\ Augusto Cezar Rodrigues ${ }^{1}$ \\ ${ }^{1}$ Universidade Federal de Viçosa, Labarótorio de Pesquisas de Produtos Naturais, Departamento de Química, Viçosa, MG 36.570-000, Brazil \\ ${ }^{2}$ Institute of Organic Chemistry, Bulgarian Academy of Sciences, 1113 Sofia, Bulgaria
}

\begin{abstract}
Reverse-phase HPLC with refractive index and light scattering detectors in isocratic and gradient elution modes, respectively, was applied for the separation of the major triacylglycerols (TAG) in coffee lipids. Twelve TAG species could be identified and determined using a linear gradient of acetonitrile in dichloromethane: dichloroethane. The quantitative evaluation was based on the relative area percentages derived directly from a data-station. The procedure was applied to determine the TAG composition of three types of coffee beans harvested in two coffee producing areas in Brazil and dried by two commonly used procedures. No significant differences in the TAG compositions due to the type, origin and drying procedure were found. Copyright $(C) 2003$ John Wiley \& Sons, Ltd.

Keywords: Reverse-phase HPLC; triacylglycerols; coffee beans; quality; storage; drying.
\end{abstract}

\section{INTRODUCTION}

Most of the Brazilian coffee produced for internal consumption is considered to be of low quality, and a number of factors such as poor harvesting and post harvesting practices (Informe Agropecuário, 1997), fungal contamination (Zambolin et al., 1996) and the presence of undesired composts (Spadone et al., 1990) have been suggested as possible causes. Although information concerning coffee lipids is very limited (Kaufmann and Hamsagar 1962; Nikolova-Damyanova et al., 1998; Jham et al., 2001), these components have been considered to be associated with the low quality of the product perhaps due to the hydrolysis of triacylglycerols (TAGs) with the release of free fatty acids which are then oxidised (Multon et al., 1973; Wajda and Walczyk, 1978; Speer et al., 1993).

As a preliminary part of a research programme to study the role of lipids in the quality of Brazilian coffee, we have reported the TAG composition of cherry coffee beans using silver ion and reverse-phase TLC in a complementary manner (Nikolova-Damyanova et al., 1998). However, this technique, whilst giving reliable results, was found to be somewhat tedious and unsuitable for the analysis of the large number of coffee samples required in the programme. We have therefore evaluated reversephase (RP) HPLC methods employing a refractive index detector (RID) and a light scattering detector (LSD) in order to establish a simple and rapid procedure for

* Correspondence to: G. N. Jham, Universidade Federal de Viçosa, Labarótorio de Pesquisas de Produtos Naturais, Departamento de Química, Viçosa, MG 36.570-000, Brazil.

Email: gulab@ufv.br

Contract/grant sponsor: FAPEMIG

Contract/grant sponsor: Bulgarian Scientific Fund; Contract/grant number: $\mathrm{X}-1009$.

Contract/grant sponsor: $\mathrm{CNP}_{\mathrm{q}}$. the determination of the major TAG species in coffee samples.

\section{EXPERIMENTAL}

Coffee samples. About $10 \mathrm{~kg}$ of coffee beans (Coffea arabica L.; Catuaí Vermelho) were harvested in Machado or Viçosa (Minas Gerais, Brazil) by the 'derriça' method (that is beans were removed by hand from the tree and allowed to drop to the floor which had been covered with a cloth). From this population, a mixture of beans was obtained by separating $5 \mathrm{~kg}$ randomly. From the remainder of the population, the immature and cherry beans were separated by placing the beans in a tank containing $50 \mathrm{~L}$ of water. The dry beans floated immediately and were removed, while the immature and cherry beans remained at the bottom of the tank. After draining the tank, the immature and the cherry beans were separated by hand and allowed to dry in the air for $20 \mathrm{~h}$. One portion of each of the samples of beans so obtained [i.e. random mixture (Viçosa beans only), immature and cherry] was dried separately in a conventional dryer at $40^{\circ} \mathrm{C}$ for $40 \mathrm{~h}$ to ca. $12 \%$ humidity. The other portion (Viçosa beans only) was dried on a patio for $10-12$ days to a humidity of ca. $14 \%$. In this way a total of eight bean samples $\left(T_{1}-T_{8}\right)$ were obtained (Table 1).

Extraction of lipids. Dried coffee beans were finely ground and extracted for $6 \mathrm{~h}$ in a Soxhlet extractor with hexane. The resulting extract was dried over anhydrous sodium sulphate, evaporated under reduced pressure at $35^{\circ} \mathrm{C}$ and stored in a freezer. TAGs were analysed either directly in the hexane extracts or following purification by preparative TLC on silica gel layers as described previously (Nikolova-Damyanova et al., 1998). 
Table 1. Key to the coffee bean samples (type, origin and treatment) analysed by RP-HPLC in the present study

Description of sample Treatment code

Immature coffee beans obtained in Viçosa and dried in a dryer Random mixture of coffee beans obtained in Viçosa and dried on a dryer

Cherry coffee beans obtained in Viçosa and dried in a dryer Immature coffee beans obtained in Viçosa and dried on a patio

Random mixture of coffee beans obtained in Viçosa and dried on a patio

Cherry coffee beans obtained in Viçosa and dried on a patio

Immature coffee beans obtained in Machado and dried in a dryer

Cherry coffee beans obtained in Machado and dried in a dryer

Preparation of TAG standards. The isolation of the main TAG classes from cherry coffee beans, namely $S_{2} D$, $\mathrm{SD}_{2}, \mathrm{SMD}$ and $\mathrm{S}_{2} \mathrm{M}$ [for abbreviations see footnote (b) to Table 2] was performed by preparative silver ion TLC using TAGs isolated from cherry coffee beans (RB Tarandjiska, personal communication).

HPLC analysis. Gradient elution analysis was performed using a GBC (Victoria, Australia) model 1150 HPLC pump equipped with a Rheodyne (Rohnert Park, CA, USA) injector, an ACS (Macclesfield, UK) model 570/ 14 LSD, a Shimadzu (Kyoto, Japan) model CBM-101 work station and a Techsphere (HPLC Technology, Macclesfield, UK) ODS column $(250 \times 4.6 \mathrm{~mm}$ i.d; $5 \mu \mathrm{M})$ and guard-column $(10 \times 4.6 \mathrm{~mm}$ i.d; $5 \mu \mathrm{M})$. TAGs were eluted with a linear gradient of acetonitrile (solvent A) and dichloromethane:dichloroethane $(8: 2, \mathrm{v} / \mathrm{v}$; solvent $\mathrm{B}$; Nikolova-Damyanova et al., 1990) from $55: 45$ to $65: 35$ (A:B) in $40 \mathrm{~min}$ at a flow rate of $0.5 \mathrm{~mL} / \mathrm{min}$. Isocratic elution was performed using a Shimazdu model LC-6 AD HPLC system equipped with a Rheodyne injector, a Shimazdu model 10A RID, a Shimadzu model CBM101 data acquisition system and a Techsphere ODS column and guard-column (as described above). TAGs were eluted with acetonitrile:acetone $(1: 1, v / v)$ at a flow rate of $2 \mathrm{~mL} / \mathrm{min}$. The TAG standards and the oils obtained from the hexane extraction of coffee samples were dissolved in hexane $(10 \mu \mathrm{g} / \mu \mathrm{L})$ and filtered prior to injection. Sample sizes of 10 and $20 \mu \mathrm{L}$ were injected for LSD and RID, respectively. The quantitative proportions of the individual components in the samples were derived directly form the data system as relative area percentages.

Statistics. The experiment was arranged in a completely random fashion involving eight treatments and three replicates for each treatment. The relative percentages of the TAGs were analysed statistically at the 5\% significance level (Scott and Knott, 1974).

\section{RESULTS AND DISCUSSION}

The classes $\mathrm{S}_{2} \mathrm{D}, \mathrm{SD}_{2}, \mathrm{SMD}$ and $\mathrm{S}_{2} \mathrm{M}$ of unsaturated TAGs were chosen as references because they represent about $80 \%$ of the total TAGs in coffee beans. The expected species of TAG, the respective partition numbers and relative proportions (Nikolova-Damyanova et al., 1998) are listed in Table 2. Initially, each reference TAG

Table 2. Separation of TAG standards in individual classes by silver ion TLC and RP-HPLC using RID and LSD

\begin{tabular}{|c|c|c|c|c|c|}
\hline \multirow[b]{2}{*}{ TAG classes ${ }^{a, b}$} & \multirow[b]{2}{*}{ TAG Species ${ }^{a, c}$} & \multirow[b]{2}{*}{ Partition Number ${ }^{a}$} & \multicolumn{3}{|c|}{ Content of TAG (\%) determined by } \\
\hline & & & Silver ion TLC ${ }^{a}$ & RP-HPLC with RID & RP-HPLC with LSD \\
\hline \multirow[t]{4}{*}{$\mathrm{S}_{2} \mathrm{M}$} & PPO & 48 & 68 & 42.6 & 63.5 \\
\hline & PStO & 50 & 23 & 37.3 & 24.7 \\
\hline & PAO & 52 & 8 & 20.1 & 8.1 \\
\hline & PBO & 54 & 2 & $n d^{d}$ & nd \\
\hline \multirow[t]{5}{*}{$\mathrm{S}_{2} \mathrm{D}$} & PPL & 46 & 64 & 63.5 & 62.8 \\
\hline & PStL & 48 & 21 & 26.6 & 28.0 \\
\hline & $P A L+S t S t L$ & 50 & 10 & 9.9 & 9.9 \\
\hline & $\mathrm{PBL}+\mathrm{StAL}$ & 52 & 2.0 & nd & nd \\
\hline & $\mathrm{PBL}+\mathrm{StAL}$ & 54 & 1 & nd & nd \\
\hline \multirow[t]{3}{*}{ SMD } & POL & 46 & 70 & 87.0 & 65.5 \\
\hline & StOL & 48 & 23 & 12.3 & 21.9 \\
\hline & AOL & 50 & 6 & 0.47 & 5.09 \\
\hline \multirow[t]{4}{*}{$\mathrm{SD}_{2}$} & PLL & 44 & 62 & 75.8 & 82.1 \\
\hline & StLL & 46 & 20 & 8.9 & 16.1 \\
\hline & ALL & 48 & 16 & 5.2 & 1.9 \\
\hline & BLL & 50 & 2 & nd & nd \\
\hline
\end{tabular}

a Based on Nikolova-Damyanova et al. (1998).

b $\mathrm{S}$, saturated-; M, monoenoic-; D, dienoic fatty acid moiety.

${ }^{c} \mathrm{P}$, palmitic-; St, stearic-; A, arachidic-; B, bechenic-; O, oleic-; L, linolenic acid residue.

${ }^{\mathrm{d}}$ nd, not determined. 


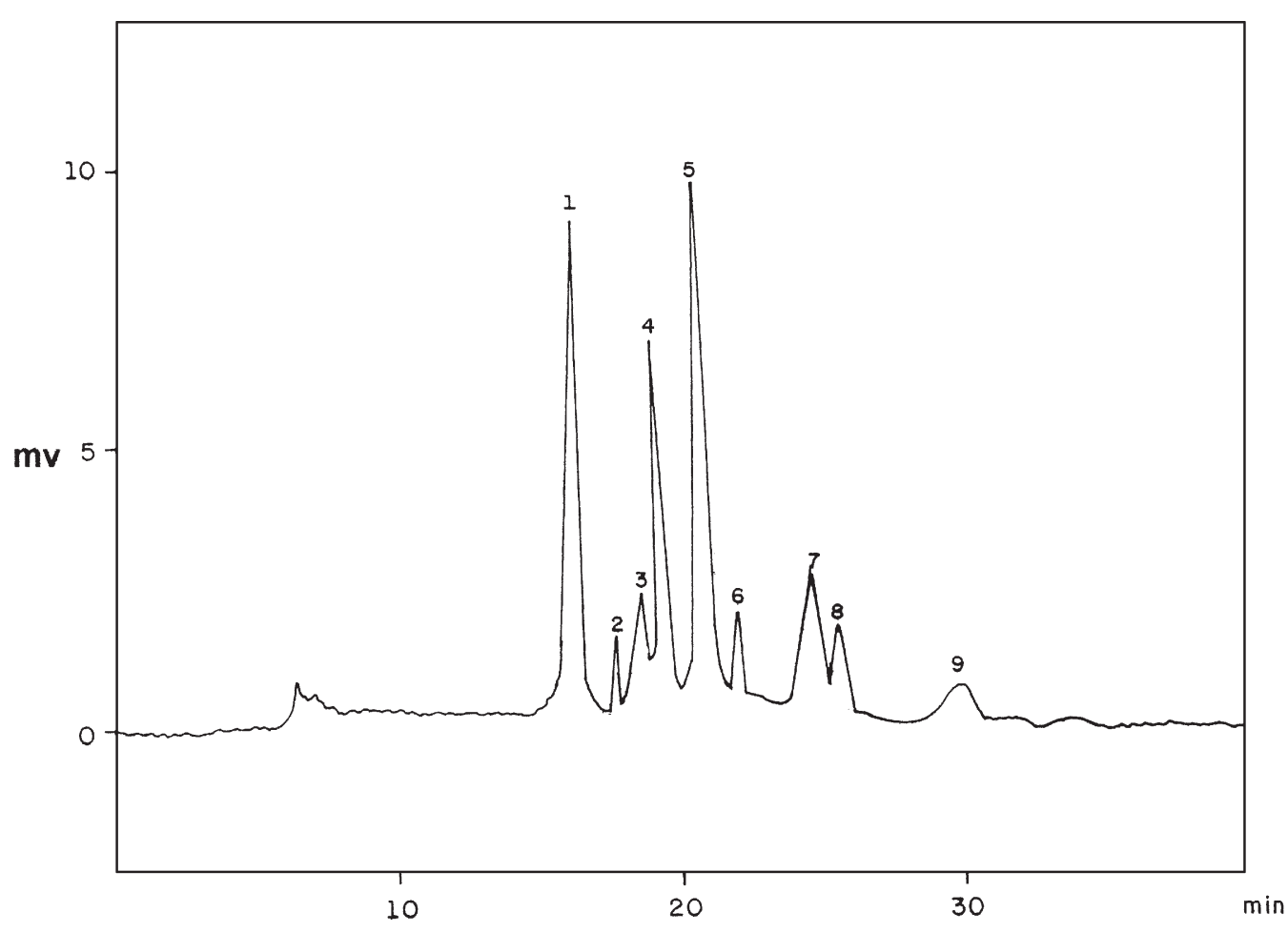

Figure 1. RP-HPLC chromatogram of the four major lipid classes $S_{2} M, S_{2} D, S M D$ and $S_{2}$ detected by LSD following gradient elution. Key to peak identity: 1, PLL; 2, OOL; 3, StLL; 4, POL; 5 , PPL; 6, POO + ALL; 7, PStL; 8, PPO; and 9, PStO. [For abbreviations see footnotes (b) and (c) of Table 2; for details of the chromatographic protocol see Experimental section.]

class was subjected separately to RP-HPLC using either isocratic elution mode with RID or gradient elution mode with LSD. Different mobile phases were tested and the most acceptable results were obtained with the solvents described in the experimental section. All of the expected TAG species, namely PPO, PStO and PAO $\left(\mathrm{S}_{2} \mathrm{M}\right.$ class $)$, PPL, PStL and PAL $+\mathrm{StStL}\left(\mathrm{S}_{2} \mathrm{D}\right.$ class $)$, POL, StOL and AOL (SMD class), and PLL, StLL, ALL ( $\mathrm{SD}_{2}$ class) could clearly be detected using separate standards [for abbreviations see footnotes (b) and (c) to Table 2]. As can be seen from Table 2, the relative area percentages of the TAGs varied depending on the detector employed. As expected, the values obtained by LSD typically agreed much better with previous results (Nikolova-Damyanova et al., 1998).

A typical HPLC-LSD chromatogram of a mixture of the four reference TAG classes $\left(\mathrm{S}_{2} \mathrm{M}, \mathrm{S}_{2} \mathrm{D}, \mathrm{SMD}\right.$ and $\mathrm{SD}_{2}$ ) obtained using a linear gradient of acetonitrile in dichloromethane:dichloroethane is shown in Fig. 1. As can be seen, the number of peaks recorded was lower than expected due to peak overlap. Nine peaks could, however, be clearly separated and identified with the help of standards as (in order of elution) PLL, OOL, StLL, POL, PPL, POO + ALL, PStL, PPO and PStO. Using isocratic elution, only six peaks could be identified, namely PLL, StLL + POL, PPL + OOL, ALL, StOL + PStL + POO and PStO. The detection of minor TAGs was not attempted owing to the limited amount of standards available. Furthermore, some of the minor peaks detected by TLC were not identified by RP-HPLC since appropriate standards were not available.

A requirement of our research programme was to evaluate a large number of coffee samples, and hence it was important to develop a rapid and easy method for the separation and quantitative (\%) evaluation of the major TAG species. Previous results have shown that the hexane extract consists of ca. 75\% TAG together with free fatty acids, monoacylglycerols, diacylglycerols, terpene esters and free sterols (Nikolova-Damyanova et al., 1998). Hence, it was important to know whether it was essential to purify the hexane extract prior to RPHPLC analysis even though this would incur extra time and labour. TAGs from a coffee sample (treatment $\mathrm{T}_{3}$ ) were, therefore, purified by TLC (Nikolova-Damyanova et al., 1998) and analysed by RP-HPLC using gradient elution and LSD. Comparison of this chromatogram (Fig. 2A) with that obtained directly from the crude hexane extract (Fig. 2B; see below) showed that the region where the TAGs eluted was essentially the same. All further analyses were conducted using crude hexane extracts.

The typical HPLC-LSD chromatogram, obtained using gradient elution, of a crude hexane extract of coffee beans (Fig. 2B) showed a clean, smooth base line with good resolution and apparently all major peaks could be easily identified. The analysis was quite reproducible, and 12 peaks representing LLL, StLLn, OLL, PLL, OOL, StLL, POL, PPL, POO + ALL, PStL + StOL, PPO and PStO could be determined. It should be noted that LLL, StLLn and OLL were only identified tentatively based on knowledge of the TAG composition of coffee (Nikolova-Damyanova et al., 1998) and literature data (Christie, 1987). With isocratic elution, only nine peaks could be identified as LLL, StLLn, OLL, PLL, StLL + POL, PPL + OOL, ALL, StOL + PStL + POO and PPO. Since, as expected, better resolution was obtained using gradient elution and LSD, this procedure was applied further to determine the TAG composition of the various coffee samples studied. 

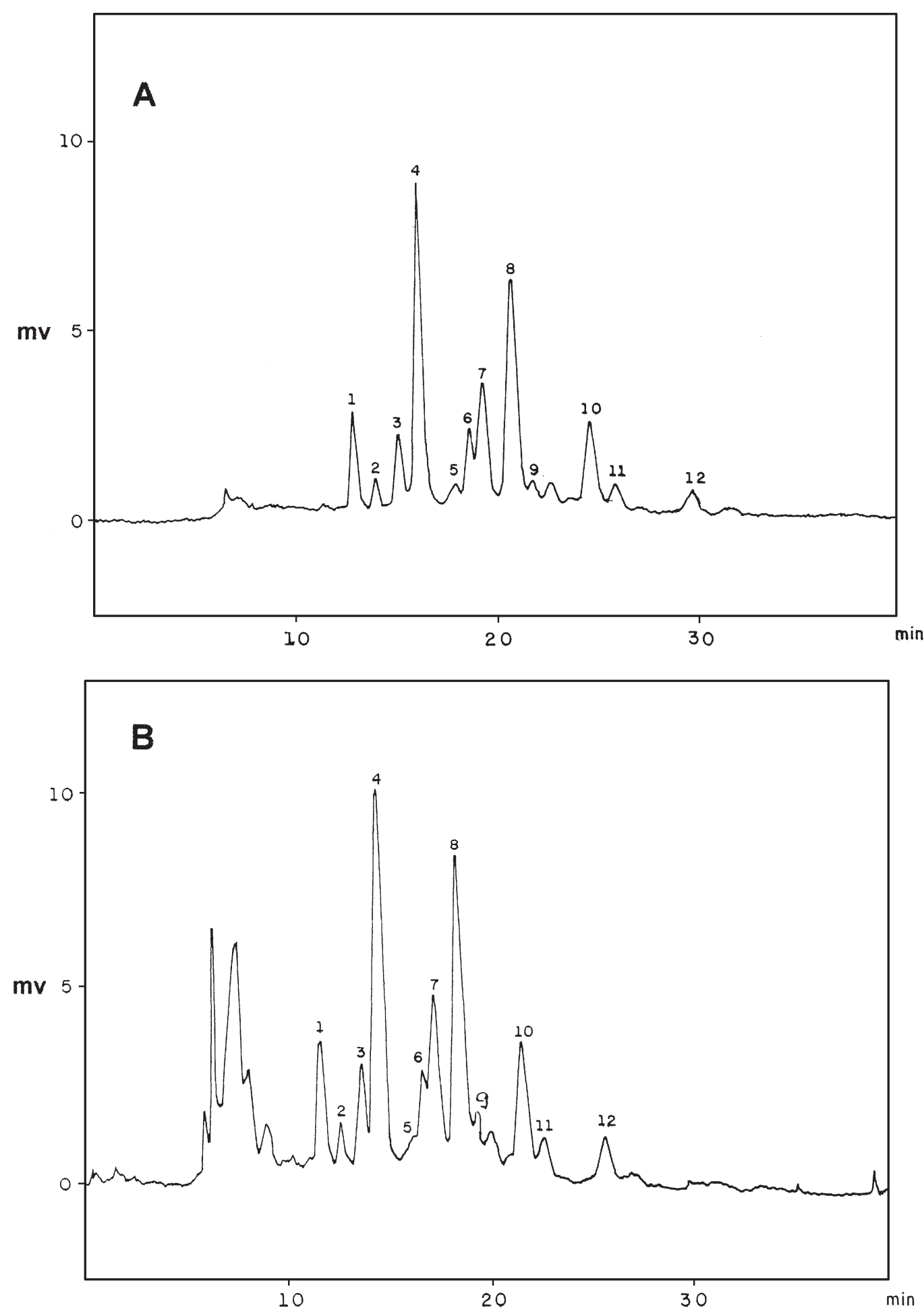

Figure 2. RP-HPLC chromatograms of (A) a purified TAG fraction, and (B) a crude hexane extract, from a cherry bean coffee sample $\left(\mathrm{T}_{3}\right)$ detected by LSD following gradient elution. Key to peak identity: 1, LLL; 2, StLLn; 3, OLL; 4, PLL; 5, OOL; 6, StLL; 7, POL; 8, PPL; 9, POO + ALL; 10, PStL + StOL; 11, PPO; and 12, PStO. [For abbreviations see footnote (c) of Table 2; for details of the chromatographic protocol see Experimental section.]

\section{Effects of bean type, drying procedures and origin on the TAG composition}

No significant effect $(p>0.05)$ of bean type was observed (Table 3 ) in the proportion of the TAGs identified in this study (i.e. LLL, StLLn, OLL, PLL, OOL, StLL, POL, PPL, POO + ALL, PStL, PPO and PStO) for samples obtained in Viçosa (treatments $\mathrm{T}_{1}-\mathrm{T}_{3} ; \mathrm{T}_{4}-\mathrm{T}_{6}$ ) and Machado (treatments $T_{7}$ and $T_{8}$ ). Similarly, there was no significant effect $(p>0.05)$ of the method of drying employed on the proportion of TAGs of immature coffee beans (treatments $\mathrm{T}_{1}$ and $\mathrm{T}_{4}$ ) or cherry coffee beans (treatments $T_{3}$ and $T_{6}$ ). These results were in agreement with previous findings (Jham et al., 2001). Although coffee drying processes have been extensively examined (Illy and Viani, 1995), few studies have been conducted on chemical changes accompanying the drying procedure. 
Table 3. TAG composition of the hexane extracts of eight coffee samples determined by RP-HPLC with LSD

\begin{tabular}{|c|c|c|c|c|c|c|c|c|c|c|c|c|}
\hline \multirow[b]{2}{*}{ Sample $^{\mathrm{a}}$} & \multicolumn{12}{|c|}{ Content of TAG $(\%)$ determined by RP-HPLC with LSD } \\
\hline & $\mathrm{LLL}^{\mathrm{c}}$ & StLLn ${ }^{c}$ & $\mathrm{OLL}^{\mathrm{c}}$ & $\mathrm{PLL}^{\mathrm{c}}$ & $\mathrm{OOL}^{\mathrm{c}}$ & StLL ${ }^{c}$ & $\mathrm{POL}^{\mathrm{c}}$ & $\mathrm{PPL}^{\mathrm{c}}$ & $\mathrm{POO}+\mathrm{ALL}^{\mathrm{c}}$ & $\mathrm{PStL}^{\mathrm{c}}$ & $\mathrm{PPO}^{\mathrm{c}}$ & $\mathrm{PStO}^{\mathrm{c}}$ \\
\hline $\mathrm{T}_{1}$ & 5.88 & 1.83 & 4.93 & 26.92 & 1.05 & 5.15 & 11.38 & 25.98 & 1.43 & 9.67 & 2.38 & 3.64 \\
\hline $\mathrm{T}_{2}$ & 5.69 & 1.90 & 5.23 & 26.74 & 1.42 & 5.41 & 11.41 & 25.15 & 1.35 & 9.71 & 2.35 & 3.58 \\
\hline $\mathrm{T}_{3}$ & 6.41 & 1.71 & 5.30 & 26.89 & 0.98 & 5.28 & 11.16 & 25.18 & 1.63 & 9.58 & 2.05 & 3.64 \\
\hline $\mathrm{T}_{4}$ & 6.45 & 1.75 & 5.60 & 27.18 & 0.81 & 5.79 & 11.25 & 23.90 & 1.31 & 9.88 & 2.88 & 3.75 \\
\hline$T_{5}$ & 5.92 & 1.84 & 5.65 & 27.54 & 1.66 & 5.28 & 11.88 & 24.80 & 1.63 & 9.84 & 2.87 & 3.02 \\
\hline $\mathrm{T}_{6}$ & 5.68 & 1.92 & 5.52 & 26.88 & 1.53 & 4.94 & 11.91 & 25.33 & 1.56 & 9.71 & 2.33 & 3.62 \\
\hline $\mathrm{T}_{7}$ & 6.64 & 1.79 & 5.42 & 26.75 & 1.74 & 5.67 & 11.99 & 24.24 & 1.58 & 9.73 & 2.06 & 3.33 \\
\hline $\mathrm{T}_{8}$ & 6.49 & 2.07 & 6.17 & 26.58 & 1.12 & 5.36 & 11.31 & 24.24 & 1.60 & 9.50 & 2.40 & 3.13 \\
\hline
\end{tabular}

a See Table 1 for sample description and treatment.

${ }^{\text {b }} \mathrm{P}$, palmitic-; St, stearic-; A, arachidic-; B, bechenic-; O, oleic-; L, linolenic acid residue.

c Mean value $(n=3)$; values in each column showed no significant differences at $5 \%$ probability by the Scot-Knott test.

Further, no significant effect $(p>0.05)$ of origin of coffee was observed in the proportion of the TAGs of immature coffee beans (treatments $\mathrm{T}_{1}$ and $\mathrm{T}_{7}$ ) and cherry coffee beans (treatments $\mathrm{T}_{3}$ and $\mathrm{T}_{8}$ ), even though Machado and Viçosa are known to produce coffee of good and poor quality, respectively. It was not possible to compare these results with literature data since no similar experiments have been conducted with coffee.

In conclusion, although lipids are known to play an important role in the quality of several crops such as soybean, cacao, nuts, there is no such evidence in coffee in spite of speculations of involvement of lipids in coffee quality. We have determined for the first time the indi- vidual TAGs in coffee samples and found that there was no influence of bean maturity, drying procedure and geographic origin on the TAG composition. The implications of these findings with respect to beverage quality are presently not clear.

\section{Acknowledgements}

The authors would like to thank the Brazilian agencies (FAPEMIG) and the Bulgarian Scientific Fund (project X-1009) for their partial financial support. Fellowships to GNJ and ACR from the Brazilian agency $\mathrm{CNP}_{\mathrm{q}}$ are also gratefully acknowledged.

\section{REFERENCES}

Christie WW. 1987. High Performance Liquid Chromatography and Lipids. Pergamon Press: Oxford.

Illy A, Viani R. 1995. Expresso Coffee: The Chemistry of Quality. Academic Press: London.

Informe Agropecuário. 1997. Qualidade do Café 18: 1-76.

Jham GN, Velikova R, Muller $H$, Nikolova-Damyanova B, Cecon PR. 2001. Lipid classes and triacylglycerols in coffee samples from Brazil: effects of coffee type and drying procedures. Food Res Int 34: 111-115.

Kaufmann HP, Hamsagar RS. 1962. Zur Kentnis der Lipoide der Kaffeebohne. I: Ueber Fettsaure des Cafestols. Fette Seifen Anstrichmittel 64: 206-213.

Multon JL, Poisson B, Cachaginer M. 1973. Evolution de plusieurs caratéristiquers d'un café Arabica au cours d'un stockage expérimental effectuéà 5 humidités relatives et 4 températures différentes. Proceedings of the 6th ASIC Colloquium; 268-277.

Nikolova-Damyanova B, Christie WW, Herslof B. 1990. The structure of the triglycerides of meadowfoam oil. J Am Oil Chem Soc 67: 503-507.
Nikolova-Damyanova B, Velikova R, Jham GN. 1998. Lipid classes, fatty acid composition and triacylglycerol molecular species in crude coffee beans harvested in Brazil. Food Res Int 31: 479-486.

Scott AJ, Knott MA. 1974. A cluster analysis method for grouping means in the analysis of variance. Biometrics 30: 507-512.

Spadone JC, Takeoke G, Liardo, R. 1990. Analytical investigation of rio off-flavour in green coffee. J Agric Food Chem 38: 226-233.

Speer K, Sehat N, Montang A. 1993. Fatty acids in coffee. Proceedings of the 15th ASIC Colloquium; 583-592.

Wajda P, Walczyk D. 1978. Relationship between acid values of extracted fatty matter and age of green coffee bean. $J$ Sci Food Agric 29: 237-380.

Zambolim L, Sondhal M, Fernandes NT. 1996. Microorganismos associados à qualidade de bebida de café. In Relatório Anual Sobre a Qualidade da Bebida. Universidade Federal de Viçosa: Viçosa; 1-55. 